\title{
Eyewitness Memory Enhancement in the Police Interview: Cognitive Retrieval Mnemonics Versus Hypnosis
}

\author{
R. Edward Geiselman \\ University of California, Los Angeles \\ Ronald P. Fisher \\ Florida International University \\ David P. MacKinnon and Heidi L. Holland \\ University of California, Los Angeles
}

\begin{abstract}
This research compared the effectiveness of three interview procedures for optimizing eyewitness memory performance: (a) the "cognitive interview" based on memory-retrieval mnemonics from current memory theory, (b) the presently controversial hypnosis interview, and (c) the standard (control) police interview. These methods were evaluated empirically in a controlled, yet ecologically valid, laboratory setting. Eighty-nine subjects viewed police training films of simulated violent crimes and were questioned individually in interactive interviews 48 hours later by experienced law-enforcement personnel. Both the cognitive and hypnosis procedures elicited a significantly greater number of correct items of information from the subjects than did the standard interview. This result, which held even for the most critical facts from the films, was most pronounced for crime scenarios in which the density of events was high. The number of incorrect items of information generated did not differ across the three interview conditions. The observed memory enhancement was interpreted in terms of the memory-guidance techniques common to both the cognitive and hypnosis interviews. Neither differential questioning time nor heightened subject or interviewer motivation could explain the results.
\end{abstract}

The Rand Corporation (1975), in a comprehensive study of criminal-investigation processes, reported that the principal determinant of whether or not a case is solved is the completeness and accuracy of the eyewitness account. Nevertheless, eyewitness reports are known to be incomplete, unreliable, partially constructed (confabulated), and malleable during the questioning procedure (Clifford \& Hollin, 1983; Loftus, 1975, 1979; Loftus, Miller, \& Burns, 1978; Wells, Ferguson, \& Lindsay, 1981). The purpose of the present study, therefore, was to suggest methods to enhance the accuracy of eyewitness

This research was supported by a grant from the National Institute of Justice (USDJ-83-IJ-CX-0025). We thank the 17 law-enforcement volunteers who served as the interviewers and Lisa Hutton, Diane Sindel, Kim O'Reilly, Robin Cohen, and Phil Garnier, who played integral roles in the conduct and analysis of the experiment. We also express our appreciation to the Los Angeles Police Department and the Inglewood Police Department for their co-operation in this project.

Requests for reprints should be sent to $R$. Edward Geiselman, Department of Psychology, University of California, Los Angeles, California 90024. reports and to test these methods empirically in a controlled, yet ecologically valid, laboratory setting.

Research on eyewitness memory retrieval has produced few positive suggestions for law-enforcement personnel. Two notable exceptions involve the ordering of the questions to be asked during the interview and the phrasing of the questions. First, the witness should be asked to report the incident in their own words before being asked any specific questions (Geiselman et al., 1984; Hilgard \& Loftus, 1979; Timm, 1983). This procedure reduces the possibility of the interviewer leading the witness, and the information given by a witness during a free report has been found to be more accurate, although more incomplete, than information given in response to specific questions. Second, to further avoid leading the witness, the specific questions should be phrased using indefinite articles rather than definite articles (Loftus \& Zanni, 1975). A third, guidedmemory technique was shown to facilitate eyewitness recognition performance in lineup procedures (Malpass \& Devine, 1981); 
but with the exception of Geiselman et al. (1984), little has been done to follow up on such memory-enhancement techniques.

Otherwise, as noted by Clifford and LloydBostock (1983), "The work in the eyewitness field [has been] essentially negativistic. . . . In short, the witness [has been] shown to be a somewhat pathetic figure in the face of extramemorial factors occurring at encoding, during storage or at retrieval" (p. 286). Yuille (1980) has proposed that considerable effort now be focused on how we can improve eyewitness performance. Wells (1978) made a similar argument with his distinction between variables that can be manipulated to reduce eyewitness fallibility (system variables) and those that cannot be controlled in actual crime cases (estimator variables). He concluded that system-variable research has greater potential for positive contributions to criminal justice.

One dramatic technique for eyewitness memory enhancement is the hypnosis interview. Hypnosis has been reported to be useful in criminal cases (Reiser, 1974, 1976; Reiser \& Nielsen, 1980; Schafer \& Rubio, 1978; Stratton, 1977), especially when trauma to the witness is involved. Enhanced memory under hypnosis also obtains in some controlled laboratory experiments (DePiano \& Salzberg, 1981; Griffin, 1980; Stager \& Lundy, 1985). On the whole, though, the evidence about memory under hypnosis is mixed. Many studies find no memory enhancement with hypnosis (see M. Smith, 1983, for a review). Of greater practical consequence, hypnosis may distort the memory process. It has been suggested that hypnotized subjects (a) introduce fabrications into their reports and exhibit increased error rates (Diamond, 1980; Dywan \& Bowers, 1984; Orne, 1979), (b) are more susceptible to leading questions (Putnam, 1979; Sanders \& Simmons, 1983), and (c) are more likely to view distorted memories as being accurate (Orne, 1961; Sheehan \& Tilden, 1983). In addition, the accuracy of information generated under hypnosis appears to be unrelated to the witnesses' confidence in the information (Zelig \& Beidleman, 1981). The case against hypnosis also is equivocal, as some researchers have found hypnosis to improve memory without showing increased confabulation or greater susceptibility to misleading questions (Griffin, 1980; Stager \& Lundy, 1985). Furthermore, even nonhypnotized witnesses are highly subject to memory alterations (Loftus, 1979; Timm, 1981, 1983; Wells et al., 1981), and nonhypnotized witnesses are often inaccurate about the quality of their reports (Deffenbacher, 1980; Wells \& Lindsay, 1983). Nevertheless, as a general safeguard against the potential problems encountered with memory under hypnosis, several United States states have placed some restrictions on the admissibility of hypnosis recall in a court of law.

In light of the legal problems and the tenuous empirical support for the hypnosis interview, we set out to develop nonhypnotic mnemonics to assist police in interviewing eyewitnesses. Over the course of the last 2,000 years, persons interested in memory enhancement have developed a variety of mnemonics, ranging from the Greeks' use of imagery (method of loci) to the more modern notions of depth of processing and organization. And, whereas these mnemonics have proven effective in many learning tasks, they are inappropriate for police investigation because they must be employed at the encoding or acquisition stage. In the typical crime scenario, the events unfold rapidly under emotionally charged conditions. Eyewitness attention is most likely narrow in focus, and eyewitness memory is incidental. Therefore, effective memory search procedures are required. Our focus, then, was to develop mnemonics that could be used to facilitate the retrieval stage.

The theoretical underpinnings that guided our thinking are based on two generally accepted principles of memory. First, the memory trace is composed of several features (Bower, 1967; Underwood, 1969; Wickens, 1970), and the effectiveness of a retrieval cue is related to the amount of feature overlap with the encoded event (Flexser \& Tulving, 1978). Second, there may be several retrieval paths to the encoded event, so that information not accessible with one retrieval cue may be accessible with a different cue (Tulving, 1974). Based on this theoretical framework, Geiselman et al. (1984) developed a memoryretrieval procedure for eyewitnesses called the cognitive interview that consists of four 
retrieval mnemonics. Of these, two attempt to increase the feature overlap between encoding and retrieval contexts: (a) mentally reinstating the environmental and personal context that existed at the time of the crime (Bower, Gilligan, \& Monteiro, 1981; Malpass \& Devine, 1981; S. Smith, 1979) and (b) reporting everything, even partial information, regardless of the perceived importance of the information (M. Smith, 1983). The other two mnemonics encourage using many retrieval paths: (c) recounting the events in a variety of orders (Burns, 1981; Whitten \& Leonard, 1981), and (d) reporting the events from a variety of perspectives (Anderson \& Pichert, 1978; Firstenberg, 1983).

The cognitive interview was evaluated positively in a preliminary experiment conducted by Geiselman et al. (1984). In that research, actors disrupted a classroom situation and the students were interviewed subsequently as eyewitnesses via a questionnaire. Students who were instructed in the four memory retrieval mnemonics at the time of test recalled more correct information about the incident than did subjects who were told simply to keep trying to remember more information. Furthermore, the cognitive interview showed none of the drawbacks sometimes found with hypnosis: It did not lead to more incorrect information being generated, nor did it lead to greater eyewitness confidence in the incorrect information. Based on these preliminary results, the cognitive interview represents a promising alternative to the hypnosis interview.

Although the results from Geiselman et al. (1984) are encouraging, one major limitation in that study was that the conditions of the experiment were somewhat dissimilar to those found in a real crime. The "crime" itself was a low-arousal innocuous event, and the "interview" was an impersonal, standardized, written questionnaire. The present study was designed to maximize the ecological validity of the results: The stimulus materials were emotionally arousing films of simulated crimes; the eyewitness recall protocols were collected using interactive interviews rather than fixed questionnaires; and the interviews were conducted by experienced law enforcement personnel. The present study also extended the earlier work of Geiselman et al. by comparing the cognitive interview to the hypnosis interview and to the standard (control) police interview. Each of these procedures is described in detail in the Method section below. The three types of interview were compared on (a) the number of correct items of information elicited, (b) the number of incorrect items of information elicited, and (c) the number of confabulated items of information generated.

\section{Method}

\section{Subjects}

The subjects were 89 undergraduate students, 55 males and 34 females, recruited from three introductory psychology classes and one psychology of learning class at the University of California, Los Angeles. Before agreeing to participate in the study, all subjects were informed that (a) they would be viewing a film depicting a violent crime, (b) they would be interviewed about the contents of the film by an experienced law enforcement professional, and (c) approximately one third of them would be interviewed while under hypnosis.

Subjects from the introductory psychology classes were offered $2 \mathrm{hr}$ of credit toward completion of their experiment participation requirement. Subjects from the learning course were offered no inducement.

\section{Interviewers}

The interviewers were recruited principally through an announcement placed in the International Journal of Investigative and Forensic Hypnosis. Additional participants were obtained from various police departments in Southern California. The final group of interviewers, 16 men and 1 woman, represented a variety of professions within the law enforcement domain: police detectives, Central Intelligence Agency investigators, polygraph specialists, and private detectives. To ensure homogeneity among the interviewers, each interviewer had completed a 40-hr course on forensic hypnosis and had subsequent field experience on hundreds of cases. Each interviewer was offered a $\$ 70.00$ honorarium for their participation.

Each interviewer was randomly assigned to one of the three interview conditions (cognitive $=6$, hypnosis $=7$, and standard $=4$ ). The results of the interviews suggested that the interviewer population was homogeneous given that the effect of interviewer within interview conditions was not significant (see the Results and Discussion section).

Three of the 17 interviewers had seen one or two of the films described below, but over two years had passed since that exposure. The five interviews that might have been affected by this prior exposure produced data consistent with the other interviews in those interview conditions.

\section{Materials and Apparatus}

Films. The four films used in this experiment were borrowed from the training academy of the Los Angeles 
Police Department (LAPD). The academy uses these films as part of a computerized training process in which police officers are exposed to simulated, life-threatening situations (Decision Evaluation Firearms Trainer). Each film presents an audiovisual scenario of a violent crime or crime situation that lasts approximately $4 \mathrm{~min}$. The scenarios of the four films include a bank robbery, a liquor store holdup, a family dispute, and a search through a warehouse. In each film, at least one individual is shot and killed. The scenarios are realistic in that monitored physiological reactions of officers in training have been found to be comparable to reactions that would be expected in similar street situations (LAPD). The films are rich in quantifiable information including person descriptions, mannerisms, weapons, and sequences of events.

The films were projected onto a $9 \mathrm{ft}-\mathrm{by}-9 \mathrm{ft}(2.7 \mathrm{~m} \times$ $2.7 \mathrm{~m}) \mathrm{mm}$ projector equipped with 4-track nonoptical sound. All films were shown in the same large lecture hall.

Interview environment. The interviews were conducted at the Center for Computer-Based Behavioral Studies (CCBS) in the Department of Psychology at the University of California, Los Angeles. Among the facilities at CCBS are separate cubicles (approximately $6 \mathrm{ft}-\mathrm{by}-6 \mathrm{ft} ; 1.8 \mathrm{~m} \times$ $1.8 \mathrm{~m}$ ) such that several interviews can be carried out simultaneously in an undisturbed fashion.

All interviews were audio recorded on standard cassette player/recorders, and the subjects wore lapel microphones. In addition to the audio recordings, subjects in the hypnosis condition were monitored using video cameras that were mounted in every room, regardless of the interview condition. A graduate student trained in hypnosis from the Clinical Psychology program at UCLA observed the ongoing hypnosis sessions on monitors in a control room.

\section{Interview Conditions}

Three weeks prior to the interviews, each interviewer received instructions for one, and only one, of the following three interview procedures:

Standard interview. These interviewers were told to use the questioning procedures that they normally would use without a hypnotic induction procedure. The only restriction was that each "witness" was to be asked first to describe in their own words what they remembered (open-ended report). Then, and only then, were the interviewers to ask any specific questions about the film based on the witnesses's account. The practice of asking for an open-ended report first is commonly followed by most investigators that we have interviewed, and it is supported in basic research reported by Geiselman et al. (1984), Hilgard and Loftus (1979), and Timm (1983). That is, information given during the open-ended report typically is more accurate.

Hypnosis interview. In accordance with the guidelines of Orne, Soskis, Dinges, and Orne (1984) for conducting an hypnosis interview, the subjects in this condition first were to be asked to describe the film in their own words prior to any hypnosis induction. The interviewer then was to perform an hypnosis induction, and subsequently ask the witness to restate what he or she remembered from the film, followed in turn by any specific questions about the film based on the witnesses's report. Only verbal responses were to be permitted; that is, no fingermovement responses were allowed.

To preserve ecological validity, the interviewers were free to use whatever techniques they wanted to perform the hypnosis induction.

Cognitive interview. In this condition, the interviewers were to describe four general memory-retrieval techniques to the subjects before the questioning began. A four-item list of the techniques was placed in full view of the witness during the entire interview as a reference guide. Otherwise, the format of this interview was the same as that for the standard interview. The following descriptions of the techniques were read by the interviewer to the subject verbatim at the beginning of the interview:

(a) Reinstate the Context: Try to reinstate in your mind the context surrounding the incident. Think about what the surrounding environment looked like at the scene, such as rooms, the weather, any nearby people or objects. Also think about how you were feeling at the time and think about your reactions to the incident.

(b) Report Everything: Some people hold back information because they are not quite sure that the information is important. Please do not edit anything out of your report, even things you think may not be important.

(c) Recall the Events in Different Orders: It is natural to go through the incident from beginning to end. However, you also should try to go through the events in reverse order. Or, try starting with the thing that impressed you the most in the incident and then go from there, working both forward in time and backward.

(d) Change Perspectives: Try to recall the incident from different perspectives that you may have had, or adopt the perspectives of others that were present during the incident. For example, try to place yourself in the role of a prominent character in the incident and think about what he or she must have seen.

All interviewers were informed that it was preferable to err in the direction of terminating an interview prematurely if that should become necessary. In particular, the interviewers were asked to terminate an interview if the subject appeared to become more anxious about the interview as the session progressed. None of the interviews were terminated prematurely.

\section{Procedure}

Each subject participated in two sessions. During the first session, groups of 8 to 12 subjects each saw one of the four films. The subjects were asked to refrain from discussing the film among themselves. After the film, a graduate student trained in hypnosis from the Department of Psychology at UCLA informed all subjects about misconceptions concerning hypnosis and answered any questions. This presentation was based on our observations of presentations made by hypno-investigators in the field and on suggestions made by Reiser (1980) in his handbook on investigative hypnosis.

Approximately $48 \mathrm{hr}$ after viewing the film, the subjects were interviewed by the law-enforcement personnel. Upon arrival at this second session, the subjects were assigned randomly to one of the three interview conditions (cognitive $=33$, hypnosis $=30$, and standard $=26$ ). The subjects were given the eye-roll test for hypnotic suscep- 
tibility (Spiegel, 1972), and the subjects were interviewed individually in separate rooms. Each interviewer questioned approximately five subjects during the course of the day, and each interviewer interviewed at least one witness of each crime. Before each interview, the interviewer was told only the title of the crime scenario that had been witnessed by the subject (e.g., bank robbery).

\section{Analysis of Protocols}

Each tape recorded interview was transcribed by two of four different research assistants trained by the authors. The second listener filled in any information missed in the original transcription. The transcriptions of the tapes then were given to another member of the research team who categorized the information into three exhaustive lists for each film: persons, objects, and events. The persons category included physical appearance, clothing, mannerisms, and speech characteristics. The objects category included guns, knives, cars, and carried articles. The events category included movements, number of shots, interperson contacts, conversation, and general sequencing. These exhaustive lists were compiled and matched against the information contained in the four films for accuracy. Opinionated responses, such as "the suspect was nervous," were not scored and were deleted from the lists.

This catalogue of information then was used to score each subject's transcribed report for (a) the number of correct bits of information recalled, (b) the number of incorrect bits of information generated (e.g., the wrong hair color of a suspect), and (c) the number of confabulated bits of information generated (e.g., a description of a suspect's face when the face was not shown in the film). In the few cases where a subject changed a response during the interview, only the final response was scored. This scoring was carried out by five members of the research team. Each person worked independently and was randomly assigned at least one transcription from each interview condition and each film. To evaluate the reliability of this process across the interview conditions, a two-way analysis of variance (ANOVA) was performed on each of the three memory-performance variables with interview condition and scorer as the factors. Although the main effect of scorer was significant for both the number of correct items $F(4,74)=4.59, p<.003$, and the number of incorrect items $F(4,74)=2.48, p<.05$, the Scorer $X$ Interview Condition interaction was not significant in any of the three analyses (all $F_{\mathrm{s}}<1.21$, $p>.30$ ). Thus, although some scorers may have been more liberal in counting a response as correct or incorrect, these differences did not appear differentially for any one of the three interview conditions.

\section{Design and Statistical Analysis}

A 3 (interview condition) by 4 (type of crime/film) by 2 (hypnotic susceptibility: low $=1-6$, high $=7-11$ ) between-subjects ANOVA design was used. There were three memory-performance dependent variables (number of items correct, number incorrect, and number confabulated). In addition to the three memory variables, further measures of interest were questioning time (total interview time excluding casual conversation, the hypnosis induc-
Table 1

Performance Measures for the Three

Interview Procedures

\begin{tabular}{lrrr}
\hline \multicolumn{1}{c}{ Variable } & Cognitive & Hypnosis & Standard \\
\hline No. correct (C) & 41.15 & 38.00 & 29.40 \\
No. incorrect & 7.30 & 5.90 & 6.10 \\
$\begin{array}{l}\text { No. confabulated } \\
\text { Question time }\end{array}$ & 0.70 & 1.00 & 0.40 \\
$\begin{array}{l}\text { (QT): min } \\
\text { C: QT }\end{array}$ & 39.70 & 28.20 & 32.10 \\
$\quad \begin{array}{l}\text { (covariate) } \\
\text { No. questions }\end{array}$ & 39.46 & 38.77 & 29.56 \\
$\quad$ asked & 54.90 & 34.82 & 68.90 \\
\hline
\end{tabular}

tions, and the retrieval methods training) and the number of questions asked. Subject gender differences in performance also were examined.

\section{Results and Discussion}

\section{Memory-Performance Measures}

Table 1 presents five performance measures as a function of the type of interview procedure. Prior to the substantive statistical analyses of the memory-performance data, three nested, random-effects ANOVAS were conducted on the number correct, number incorrect, and number confabulated dependent variables to determine whether the scores differed reliably between interviewers within the interview conditions. The univariate $F$ with 14 and 72 degrees of freedom was computed to be $1.55(p>.12)$ for number correct, $1.51(p>.13)$ for number incorrect, and $1.23(p>.27)$ for number confabulated. Thus, the pooled error terms (the variance between subjects across interviewers within each interview condition) were used in the between-interview comparisons (Winer, 1962, p. 207) to maximize the potential power of the tests.

The main effect for the number of correct items generated was significant, $F(2,77)=$ $5.27, p<.008$. A Tukey's posttest showed that both the cognitive and hypnosis interviews elicited a greater number of correct items of information than the control interview $(p s<.05)$ but that the cognitive and hypnosis interviews did not differ. The main effect for the number of incorrect items of information generated was not significant, $F(2,77)=1.99, p>.14$. This result is unlikely 
to be a floor effect because the average error rate was $16 \%$. Furthermore, as will be described shortly, the incorrect information data are sensitive enough to show some reliable differences-between males and females. In sum then, the enhanced recall with the cognitive and hypnosis interviews reflects more effective memory retrieval and cannot be interpreted as a shift in response criterion (Dywan \& Bowers, 1983). ${ }^{1}$ The main effect for the number of confabulated items also was not significant, $F(2,77)=2.48, p>.09$. As can be seen in Table 1, given our definition of a confabulated item of information, few subjects confabulated in any of the interview conditions.

The results for the cognitive interview closely replicate those obtained by Geiselman et al. (1984), in which subjects were interviewed about a classroom intrusion using a structured questionnaire. In both experiments, a greater number of correct items of information were generated with the cognitive interview than with the control interview, and without an increase in the number of incorrect items. Thus, the cognitive interview has been shown to be useful for the enhancement of eyewitness memory performance both under conditions of experimental control and under conditions of high ecological validity.

Whereas the present study showed enhanced memory with the hypnosis interview, this is not the most frequently reported outcome of laboratory experiments designed to evaluate the effects of hypnosis on memory performance. In studies where emphasis has been placed on experimental control, hypnosis procedures most often have been shown either to not affect memory performance or they have been found to lead to more incorrect information (Orne et al., 1984). There are many differences between the present design and those of previous studies, and further research is required to specify the factors responsible for the differences in outcome. We believe the principal candidate factors to be: the nature of the materials, the interactive nature of the interviews, and the population of interviewers. The present equality of performance observed with the cognitive and hypnosis procedures is consistent with Timm's (1983) speculation that any memory- enhancement effects of the hypnosis interview lie in its memory-guidance components.

Examination of the interview recordings produced no new insight on the issue of whether witnesses are more susceptible to leading questions under hypnosis. This is because virtually no leading questions (questions containing "given" information that was not provided by the witness) were asked by the present interviewers in any of the conditions. Even though most interviewers questioned more than one witness from at least one of the crime scenarios, only one question in the 89 interviews was identified as clearly leading the witness. Given that, to our knowledge, the present study is the first to record and analyze the interviews of experienced law-enforcement investigators, this outcome itself is an important normative result. In contrast, Yuille (1984) reported the results of a survey in which a significant percentage of Canadian police personnel agreed that "direct (often leading) questions must be asked so that the witness is reminded of relevant facts" (p. 20). It is possible, therefore, that the present population of interviewers exhibited exceptional interviewing skills and/or that the college subjects who served as the eyewitnesses showed atypical memory

\footnotetext{
1 The reader may note that the percentage of correct responses (number correct/number correct + number incorrect + number confabulated) is approximately equal across the interview conditions: .84 for cognitive, .85 for hypnosis, .82 for standard). This equivalence does not imply that memory is equally good because the three groups differed in terms of the total number of responses: The cognitive (49.5) and the hypnosis (44.9) groups made more responses than did the standard (35.9) group. It has been shown in other recall studies (Roediger, 1973) that there is a tradeoff between accuracy and number of responses made: As the subject makes more responses, the percentage of incorrect responses (intrusions) increases. Thus, one must take into account both accuracy and extent of recall to measure memory properly. In the present study, the cognitive and hypnosis interviews elicited more responses without a drop in accuracy rate, testifying to their superiority over the standard interview. Without taking into account both measures (accuracy and number of responses), one might be led to the conclusion that an interview that elicited only one, but correct, response (100\% accuracy) is as effective as one that elicits one hundred, all correct, responses $(100 \%$ accuracy). The problem is similar to the speed-accuracy tradeoff: One must examine both speed and accuracy simultaneously. Equivalent accuracy rates reflect equal performance only if speed is constant across conditions.
} 
Table 2

Performance Measures for the Three Interview Procedures as a Function of Crime Scenario

\begin{tabular}{|c|c|c|c|c|c|c|c|c|c|c|c|c|}
\hline \multirow[b]{2}{*}{ Variable } & \multicolumn{3}{|c|}{ Bank robbery } & \multicolumn{3}{|c|}{ Family dispute } & \multicolumn{3}{|c|}{ Liquor store } & \multicolumn{3}{|c|}{ Warehouse } \\
\hline & C & $\mathbf{H}$ & $\mathbf{S}$ & $\mathrm{C}$ & H & S & C & H & S & C & H & $\mathbf{S}$ \\
\hline No. correct & 40.4 & 35.4 & 28.7 & 40.6 & 35.5 & 33.3 & 57.3 & 50.8 & 29.9 & 24.3 & 28.9 & 21.7 \\
\hline No. incorrect & 7.8 & 5.9 & 7.0 & 6.8 & 5.9 & 6.8 & 8.0 & 8.6 & 3.1 & 5.5 & 3.4 & 5.5 \\
\hline No. confabulated & 0.7 & 0.4 & 0.7 & 0.6 & 0.8 & 0.2 & 0.6 & 1.6 & 0.7 & 0.9 & 1.0 & 0.0 \\
\hline
\end{tabular}

Note. $\mathrm{C}=$ cognitive, $\mathrm{H}=$ hypnosis, $\mathrm{S}=$ standard.

performance. In either case, leading questions would not have been necessary to generate reasonably complete reports. There is some indication from a recent replication experiment in our laboratory (Geiselman, Fisher, MacKinnon, \& Holland, 1985) that a greater number of leading questions are asked when nonstudents serve as the witnesses ( 20 leading questions in 53 interviews). Nevertheless, even this incidence can be considered to be infrequent. A final possibility is that the interviewers were exceedingly careful in conducting the interviews because they were aware of being observed. Although this possibility would be difficult to test empirically, it does not appeal to the authors because such conservatism would have suppressed differences between the interview conditions. There were no obvious indications that the interviews were stilted.

\section{Questioning Time}

Table 1 also presents the average total time that the interviewers spent questioning the witnesses. As noted in the Method section, these times exclude any intervals spent in casual conversation or in the hypnosis inductions or cognitive retrieval methods training. The main effect for questioning time was significant, $F(2 ; 77)=5.49, p<.006$. A Tukey's posttest showed that the interviewers who used the cognitive procedure spent more time asking questions than did interviewers who used either the hypnosis or standard procedures, which did not differ. Perhaps the superior recall in the cognitive over the standard interview occurred because of the greater time spent in questioning the witnesses. Because of this possibility, the number-correct data were reanalyzed with questioning time as a covariate. The adjusted means from this analysis are presented in the bottom row of Table 1. As before, the main effect was significant, $F(2,76)=4.65, p<.02$; and a Tukey's posttest showed that both the cognitive and hypnosis interviews led to more correct information than the standard interview $(p s<.05)$.

\section{Number of Questions Asked}

The average number of questions asked in each interview condition is presented in the bottom row of Table 1 . The main effect for type of interview was significant, $F(2,77)=$ $5.87, p<.006$, with significantly fewer questions asked in both the cognitive and hypnosis conditions than in the standard condition ( $p<.05$ and $p<.01$, respectively). Thus, the memory enhancement achieved with the cognitive and hypnosis procedures cannot be explained in terms of the interviewers asking more questions. To the contrary, the cognitive and hypnosis techniques were more efficient (0.75 and 1.09 items correct per question, respectively, versus 0.42 items correct per question in the standard condition).

\section{Type of Crime Scenario}

The three memory-performance measures are presented in Table 2 as a function of the type of interview and crime scenario (film). The crime scenario interacted with the type of interview only for the number of correct items of information generated, $F(3,77)=$ $8.80, p<.001$. As can be seen in Table 2, the superiority of the cognitive and hypnosis interviews is most evident with the bank robbery and liquor store holdup scenarios. This result was not due to a ceiling effect on 
Table 3

Performance Measures for the Three Interview Procedures as a Function of Eye-Roll Score

\begin{tabular}{|c|c|c|c|c|c|c|}
\hline \multirow[b]{2}{*}{ Variable } & \multicolumn{2}{|c|}{ Cognitive } & \multicolumn{2}{|c|}{ Hypnosis } & \multicolumn{2}{|c|}{ Standard } \\
\hline & Low & High & Low & High & Low & High \\
\hline No. correct & 39.9 & 39.3 & 37.2 & 37.6 & 28.3 & 28.2 \\
\hline No. incorrect & 7.1 & 6.8 & 5.6 & 6.4 & 6.2 & 5.4 \\
\hline No. confabulated & 0.7 & 0.8 & 0.8 & 1.1 & 0.3 & 0.4 \\
\hline
\end{tabular}

Note. Low: eyeroll $=1-6$, High: eyeroll $=7-11$. (Eyeroll scores were not recorded for 3 subjects.)

the number of correct items possible in the other two films because, with each film, the highest subject score was at least three standard errors above the mean for either the cognitive or hypnosis conditions.

The authors had no a priori hypotheses regarding this interaction. However, an afterthe-fact examination of the four films revealed one striking difference between the two crime scenarios that showed a significant effect of interview method and the two that did not. In both the bank robbery and liquor store holdup, several actions occurred simultaneously, and the number of events per unit time was high. In contrast, in both the family dispute and warehouse search scenarios, the events took place in a sequential fashion at a relatively slower pace. Perhaps the guided memory-search procedures common to both the cognitive and hypnosis interviews were more beneficial when processing of the tobe-remembered information was restricted at encoding by the density of events.

\section{Hypnotic Susceptibility}

Table 3 presents the three memory-performance measures as a function of the type of interview and level of hypnotic susceptibility (as indexed by the Spiegel eye-roll score). Neither the main effect of hypnotic susceptibility nor the interaction between type of interview and hypnotic susceptibility was significant for any of the three memory-performance measures (all $F \mathrm{~s}<1$ ). The lack of significant differences, especially for the hypnosis interview, was surprising but does not affect the above interpretation of the results. In fact, this outcome is consistent with the hypothesis that the facilitative effects of the hypnosis interview lie in the memory-guid- ance procedures (Timm, 1983) and not in the induction. ${ }^{2}$

\section{Gender of Eyewitness}

The gender of the eyewitness was found to be unrelated to: (a) the number of correct items generated, $F(1,65)<1$; (b) the number of confabulated items generated, $F(1,65)<$ 1 ; and (c) questioning time, $F(1,47)=1.64$, $p>.20$. The only significant difference was found in the number of incorrect items generated, $F(1,65)=8.50, p<.005$ : Males generated a greater number of incorrect items than females ( 7.12 versus 4.92$)$. Given that this result was not accompanied by an increase in correct information, the conclusion is that the females exhibited superior memory performance. This difference did not interact with other factors in the experiment, and therefore, the conclusions drawn here about interview methods hold for both male and female eyewitnesses.

\section{Recall of Critical Facts}

The preceding analyses of the memory performance data were carried out irrespective of the relative importance of the information that was generated across the interview conditions. Therefore, 20 facts from both the bank robbery and liquor-store holdup films, where differences in overall memory perfor-

\footnotetext{
${ }^{2}$ It is interesting to note that some of the interviewers stated in an informal debriefing session that they disagreed with the belief that only a small percentage of individuals are highly susceptible to hypnosis. If one induction method fails with a given person, another method might prove effective. Perhaps with their approach, any single index of susceptibility will not reflect the level of hypnosis ultimately achieved.
} 
Table 4

Performance Measures for Twenty Critical Facts

\begin{tabular}{|c|c|c|c|c|c|c|}
\hline \multirow[b]{2}{*}{ Variable } & \multicolumn{3}{|c|}{ Bank robbery } & \multicolumn{3}{|c|}{ Liquor store } \\
\hline & $\mathrm{C}$ & $\mathbf{H}$ & $\mathbf{S}$ & $\mathrm{C}$ & $\mathrm{H}$ & $\mathbf{S}$ \\
\hline $\begin{array}{l}\text { No. correct } \\
\text { No. incorrect }\end{array}$ & $\begin{array}{r}11.2 \\
1.3\end{array}$ & $\begin{array}{r}11.9 \\
1.5\end{array}$ & $\begin{array}{l}8.5 \\
1.8\end{array}$ & $\begin{array}{r}12.7 \\
0.9\end{array}$ & $\begin{array}{r}12.8 \\
2.0\end{array}$ & $\begin{array}{l}9.9 \\
1.0\end{array}$ \\
\hline
\end{tabular}

Note. $\mathrm{C}=$ Cognitive, $\mathrm{H}=$ Hypnosis, $\mathrm{S}=$ Standard.

mance were observed, were chosen for selective scoring as the most important items of information from those crime scenarios. The lists of critical facts were generated independently by five members of the research staff, and these lists were discussed and merged in a subsequent meeting of the entire group. Then, the protocols from the 46 subjects who witnessed either of the two target films were scored for the 20 critical facts. Each protocol was scored by one member of the staff. Neither the main effect of scorer nor the Scorer $X$ Interview Procedure interaction was significant for either the number correct or number incorrect memory variables $(F s<1.03)$.

The average memory-performance scores are presented in Table 4 . The main effect for interview condition was significant only for the number of correct items of information generated, $F(2,40)=3.64, p<.04$. As in the overall analysis, both the cognitive and hypnosis procedures led to the recall of more correct items than did the standard interview $(p s<.05)$. Thus, the cognitive and hypnosis interviews were successful in the enhancement of eyewitness memory for the most critical facts, not simply for ancillary facts. These effects did not depend on the crime scenario, the gender of the witness, or the level of eyeroll score (all $F_{\mathrm{s}}<1$ ).

\section{Conclusions}

The major finding of this study is that both cognitive-retrieval mnemonics and techniques inherent in the forensic use of hypnosis are effective for the enhancement of eyewitness memory retrieval in the police interview. This was observed to be true especially for crime scenarios in which the density of events was high. We believe these effects to lie in the guided memory-search components of the cognitive and hypnosis interviews. Both of these procedures encourage the eyewitness to mentally reinstate the contextual elements that were present at the time of the crime. In addition, the hypnosis procedure frequently draws upon a videotape replay analogy with "fixed-frame" and "zoom-in" capabilities (Reiser, 1980). It is plausible that this technique, in effect, simulates components of the no-edit and varied retrieval perspectives mnemonics from the cognitive interview. In contrast, the standard interview as observed here consists mainly of repeated attempts to recall the target information, each time in the same way without supplemental memory-retrieval guidance.

Further research will delineate which of the retrieval mnemonics are most effective for the recovery of specific kinds of information. At present, it is instructive to note that the cognitive interview can be learned and applied with little training. The interviewers who carried out the cognitive interviews in the present research, for example, studied a two-page description of the cognitive methods and participated in a 15-min discussion prior to conducting the interviews. In addition to the savings in training time, the present study showed that less time is required on average to instruct a witness in the general cognitive mnemonics $(6.7 \mathrm{~min})$ than to perform an hypnosis induction (27.1 min). One further advantage of the cognitive interview is that it circumvents the present legal problems that surround the forensic use of hypnosis. However, the effectiveness of the cognitive interview relative to the hypnosis interview in cases of severe trauma to a victim or witness remains to be evaluated.

The present study evaluated the cognitive interview in a more ecologically valid setting 
than that employed by Geiselman et al. (1984). The stimulus materials were selected and presented to enhance the arousal of the witness; an interactive questioning format was followed; and the interviews were carried out by experienced law-enforcement personnel. The importance of validating laboratory data on eyewitness phenomena under more natural conditions has been stressed by other authors (Malpass \& Devine, 1980; Monahan \& Loftus, 1982; Reiser, 1980). The descrepancy between the memory-enhancement qualities of forensic hypnosis observed here and results typically obtained under more artificial conditions underscores the importance of this validation. There still are major differences between the present laboratory setting and a real-world crime. For example, the element of personal involvement can never be achieved completely in studies of this type. However, it is interesting to note that the majority of the present subjects responded to the questions using personal pronouns, in a role-playing manner, as if they had actually experienced the crime. Another potentially important factor is the element of surprise (Murray \& Wells, 1982). The present subjects knew that they eventually would be questioned about what they saw in the films. Nevertheless, the results that were obtained here with the cognitive interview are consistent with those reported by Geiselman et al. (1984) in which the subjects' memories were incidental.

Finally, the present results are not consistent with an interpretation that would attribute the enhancement of memory performance to heightened subject or interviewer motivation. First, with such an interpretation, performance in the hypnosis condition logically should have exceeded that with the cognitive interview because all subjects volunteered for the experiment only after being informed of the possibility that they would be hypnotized. Immediately before the interviews, the subjects in the cognitive condition, as well as the subjects in the standard condition, were told that they would not be hypnotized. Average performance in the hypnosis condition was not limited by a ceiling effect on the number of correct items possible. Second, it was our impression that the subjects in all conditions were well motivated in the experiment. The majority of the subjects in all conditions role played in answering the questions. Third, the interviewers were given a description only of the interview condition in which they were to participate. Furthermore, the questioning time was shortest of all for the hypnosis interview where memory performance was relatively good, and the average number of questions asked was smaller in both the cognitive and hypnosis conditions than in the standard condition. These results would appear to contradict any interpretation where the quality of the interviews is hypothesized to have been inadvertently manipulated by the interviewers. Fourth, the superiority of the cognitive and hypnosis interviews was observed for only two of the four crime scenarios, those with rapidly and simultaneously occurring events. If subjects were simply more motivated in the cognitive and hypnosis groups, we could reasonably expect the superiority to extend across all four scenarios. Fifth, there is no evidence that memory retrieval performance is improved with greater motivation in any case (Weiner, 1966). Sixth, and most important, the effects of the cognitive and hypnosis interviews were specific to the generation of correct items of information. That is, the results cannot be couched in terms of a simple shift in response criterion resulting in greater overall productivity or a willingness to please the interviewer with embellished reports in reaction to demand characteristics.

\section{References}

Anderson, R. C., \& Pichert, J. W. (1978), Recall of previously unrecallable information following a shift in perspective. Journal of Verbal Learning and Verbal Behavior, 17, 1-12.

Bower, G. (1967). A multicomponent theory of the memory trace. In K. W. Spence \& J. T. Spence (Eds.), The psychology of learning and motivation (Vol. 1, pp. 230-325). New York: Academic Press.

Bower, G. H., Gilligan, S. C., \& Monteiro, K. P. (1981). Selectivity of learning caused by affective states. Journal of Experimental Psychology: General, 110, 451-472.

Burns, M. J. (1981). The mental retracing of prior activities: Evidence for reminiscence in ordered retrieval. (Doctoral dissertation, University of California, Los Angeles, 1981). Dissertation Abstracts International, 42, 2108B.

Clifford, B. R., \& Hollin, C. R. (1983). The effects of discussion on recall accuracy and agreement. Journal of Applied Social Psychology, 13, 234-244.

Clifford, B. R., \& Lloyd-Bostock, S. M. A. (1983). 
Witness Evidence: Conclusion and prospect. In S. M. A. Lloyd-Bostock \& B. R. Clifford (Eds.), Evaluating witness evidence (pp. 285-290). New York: Wiley.

Deffenbacher, K. A. (1980). Eyewitness accuracy and confidence: Can we infer anything about their relationship? Law and Human Behavior, 4, 243-260.

DePiano, F. A., \& Salzberg, H. C. (1981). Hypnosis as an aid to recall of meaningful information presented under three types of arousal. International Journal of Clinical and Experimental Hypnosis, 29, 383-400.

Diamond, B. L. (1980). Inherent problems in the use of pretrial hypnosis in a prospective witness. California Law Review, 68, 313-349.

Dywan, J., \& Bowers, K. S. (1983). The use of hypnosis to enhance recall. Science, 222, 184-185.

Firstenberg, I. (1983). The role of retrieval variability in the interrogation of human memory. (Doctoral dissertation, University of California, Los Angeles, 1983). Dissertation Abstracts International, 44, 1623B.

Flexser, A., \& Tulving, E. (1978). Retrieval independence in recognition and recall. Psychological Review, 85 , 153-171.

Geiselman, R. E., Fisher, R. P., Firstenberg, I., Hutton, L. A., Sullivan, S., Avetissian, I., \& Prosk, A. (1984). Enhancement of eyewitness memory: An empirical evaluation of the cognitive interview. Journal of Police Science and Administration, 12, 74-80.

Geiselman, R. E., Fisher, R. P., MacKinnon, D. P., \& Holland, H. L. (1985). Eyewitness memory enhancement with the cognitive interview. Manuscript submitted for publication.

Griffin, G. R. (1980). Hypnosis: Towards a logical approach in using hypnosis in law enforcement agencies. Journal of Police Science and Administration, 8, 385389.

Hilgard, E. R., \& Loftus, E. F. (1979). Effective interrogation of the eyewitness. International Journal of Clinical \& Experimental Hypnosis, 27, 342-357.

Loftus, E. F. (1975). Leading questions and eyewitness report. Cognitive Psychology, 7, 560-572.

Loftus, E. F. (1979). Eyewitness testimony. Cambridge, MA: Harvard University Press.

Loftus, E. F., Miller, D. G., \& Burns, H. G. (1978). Semantic integration of verbal information into visual memory. Journal of Experimental Psychology: Human Learning and Memory, 4, 19-31.

Loftus, E. F., \& Zanni, G. (1975). Eyewitness testimony: The influence of the wording of a question. Bulletin of the Psychonomic Society, 5, 86-88.

Malpass, R. S., \& Devine, P. G. (1980). Realism and eyewitness identification research. Law and Human Behavior, 4, 347-358.

Malpass, R. S., \& Devine, P. G. (1981). Guided memory in eyewitness identification. Journal of Applied Psychology, 66, 343-350.

Monahan, J., \& Loftus, E. F. (1982). The psychology of law. Annual Review of Psychology, 33, 441-475.

Murray, D. M., \& Wells, G. L. (1982). Does knowledge that a crime was staged affect eyewitness performance. Journal of Applied Social Psychology, 12, 42-53.

Orne, M. T. (1961). The potential uses of hypnosis in interrogation. In A. D. Biderman \& H. Zimmer (Eds.), The manipulation of human behavior (pp. 169-215). New York: Wiley.
Orne, M. T. (1979). The use and misuse of hypnosis in court. The International Journal of Clinical and Experimental Hypnosis, 27, 311-341.

Orne, M. T., Soskis, D. A., Dinges, D. F., \& Orne, E. C. (1984). Hypnotically induced testimony. In G. L. Wells \& E. F. Loftus (Eds.), Eyewitness testimony: Psychological perspectives (pp. 171-213). Cambridge University Press.

Putnam, W. H. (1979). Hypnosis and distortions in eyewitness memory. International Journal of Clinical and Experimental Hypnosis, 27, 437-448.

Rand Corporation. (1975, October). The criminal investigation process (Vol. 1-3). Rand Corporation Technical Report R-1776-DOJ, R-1777-DOJ, Santa Monica, CA.

Reiser, M. (1974). Hypnosis as an aid in homicide investigation. American Journal of Clinical Hypnosis, 17, 84-87.

Reiser, M. (1976). Hypnosis as a tool in criminal investigation. The Police Chief, 46, 39-40.

Reiser, M. (1980). Handbook of investigative hypnosis. Los Angeles: LEHI.

Reiser, M., \& Nielsen, M. (1980). Investigative hypnosis: A developing specialty. American Journal of Clinical Hypnosis, 23, 75-84.

Roediger, H. L. (1973). Inhibition in recall from cuing with recall targets. Journal of Verbal Learning and Verbal Behavior, 12, 644-657.

Sanders, G. S., \& Simmons, W. L. (1983). Use of hypnosis to enhance eyewitness accuracy: Does it work? Journal of Applied Psychology, 68, 70-77.

Schaefer, D. W., \& Rubio, R. (1978). Hypnosis to aid the recall of witnesses. Intermational Journal of Clinical and Experimental Hypnosis, 26, 81-91.

Sheehan, P. W., \& Tilden, J. (1983). Effects of suggestibility and hypnosis on accurate and distorted retrieval from memory. Journal of Experimental Psychology: Learning, Memory, \& Cognition, 9, 283-293.

Smith, M. (1983). Hypnotic memory enhancement of witnesses: Does it work? Psychological Bulletin, 94, 387-407.

Smith, S. (1979). Remembering in and out of context. Journal of Experimental Psychology: Human Learning and Memory, 5, 460-471.

Spiegel, H. (1972). An eye-roll test for hypnotizability. The American Journal of Clinical Hypnosis, 15, 2528.

Stager, G. L., \& Lundy, R. M. (1985). Hypnosis and the learning and recall of visually presented material. International Journal of Clinical and Experimental Hypnosis, 33, 27-39.

Stratton, J. G. (1977). The use of hypnosis in law enforcement criminal investigations: A pilot program. Journal of Police Science and Administration, April, 399-406.

Timm, H. W. (1981). The effects of forensic hypnosis techniques on eyewitness recall and recognition. Journal of Police Science and Administration, 9, 188-194.

Timm, H. W. (1983). The factors theoretically affecting the impact of forensic hypnosis techniques on eyewitness recall. Journal of Police Science and Administration, $11,442-450$.

Tulving, E. (1974). Cue-dependent forgetting. American Scientist, 62, 74-82.

Underwood, B. J. (1969). Attributes of memory. Psychological Review, 76, 559-573. 
Weiner, B. (1966). The effects of motivation on the availability and retrieval of memory traces. Psychological Bulletin, 65, 24-37.

Wells, G. L. (1978). Applied eyewitness testimony research: System variables and estimator variables. Journal of Personality and Social Psychology, 36, 15461557.

Wells, G. L., Ferguson, T. J., \& Lindsay, C. C. L. (1981). The tractability of eyewitness confidence and its implications for triers of fact. Journal of Applied Psychology, 66, 688-696.

Wells, G. L., \& Lindsay, C. C. L. (1983). How do people infer accuracy? In S. M. A. Lloyd-Bostock \& B. R. Clifford (Eds.), Evaluating witness memory (pp. 4156). New York: Wiley.

Whitten, W., \& Leonard, J. (1981). Directed search through autobiographical memory. Memory \& Cognition, 9, 566-579.
Wickens, D. (1970). Encoding categories of words: An empirical approach to meaning. Psychological Review, $77,1-15$.

Winer, B. J. (1962). Statistical priniciples in experimental design. New York: McGraw-Hill.

Yuille, J. C. (1980). A critical examination of the psychological and practical implications of eyewitness research. Law and Human Behavior, 4, 335-345.

Yuille, J. C. (1984). Research and teaching with police: A Canadian example. International Review of Applied Psychology, 33, 5-23.

Zelig, M., \& Beidleman, W. B. (1981). The investigative use of hypnosis: A word of caution. International Journal of Clinical and Experimental Hypnosis, 29, 401-412.

Received July 17, 1984

Revision received September 21, 1984 